cells that have been conveyed to that organ by the arteries [3]. Several theories have been postulated to account for the low incidence of metastases to the spleen compared to other parenchymatous organs [4], including a possible role of spleen contractions in forcing the blood from the sinusoids into the splenic vein which keeps tumour cells in constant motion.

The 2 patients we describe here had spleen metastases from ovarian and colonic cancer in the absence of other distant organ involvement. These unusual presentations of advanced disease raise the question of whether an underlying condition may represent a risk factor for spleen colonisation in subjects with solid tumours. Both patients had liver cirrhosis causing portal hypertension. When the portal venous pressure rises, blood stasis, retrograde blood flow and diversion of portal blood into systemic veins, in an attempt to decompress the portal system, can occur. We suggest, that in such conditions, a neoplastic embolus may reach the spleen via the mesenteric veins and by retrograde blood flow in the splenic vein. Moreover, implantation of neoplastic cells may be facilitated by blood stasis which increases the time of contact with the splenic tissue. The 2 cases described here seem to support this hypothesis. Patient 1 had primary ovarian cancer involving the sigmoid colon and patient 2 had a primary tumour of the descending colon; the venous system of the left region of the colon drains into the portal circulation via the inferior mesenteric vein which enters the splenic vein.

Whether neoplastic cells from tumours draining into the portal system can more easily seed the spleen in patients with portal hypertension needs to be confirmed. However, based on our experience, we suggest a more careful evaluation of the spleen at intervention and during follow-up in these subjects.

1. Berge T. Splenic metastases: frequencies and patterns. Acta Pathol Microbiol Scand 1974, 82, 499-506.

2. Morgenstern L, Rosenberg J, Geller SA. Tumors of the spleen. World f Surg 1985, 9, 468-476.

3. Marymount JH Jr, Gross S. Patterns of metastatic cancer in the spleen. Am F Clin Pathol 1963, 40, 58-60.

4. Klein B, Stein M, Kuten A, et al. Splenomegaly and solitary spleen metastasis in solid tumors. Cancer 1987, 60, 100-102.

European Joumal of Cancer Vol. 31A, No. 11, pp. 1886-1887, 1995

Copyright (C) 1995 Elsevier Science Lid

Printed in Great Britain. All rights reserved

$0959-8049 / 95 \$ 9.50+0.00$
$3 \mathrm{~cm}$ [1-3] or as part of induction chemoradiotherapy [4]. Moreover, the response to induction chemo(radio)therapy may be used as a prognostic factor $[5,6]$.

Since 1990 , we have performed a prospective study of preoperative induction chemotherapy in patients with different stages of breast cancer. After clinical examination, mammography, ultrasound and cytological proof of the primary tumour, the patients were treated with cyclophosphamide $100 \mathrm{mg} / \mathrm{m}^{2}$ orally days $1-14$, doxorubicin $30 \mathrm{mg} / \mathrm{m}^{2}$ and 5 -Fluorouracil $600 \mathrm{mg} / \mathrm{m}^{2}$ intravenously (i.v.) on days 1 and 8 . Courses were repeated every 4 weeks. After two and four courses, the response of the primary tumour was assessed by palpation, mammography and ultrasound. For stable disease or progression after the first two courses, the patient underwent surgery. Responders received another two courses of chemotherapy and then surgery. Standard criteria of response according to the WHO [7] were used. The study is ongoing. However, in a recent analysis, three problems with the evaluation of response were observed in 7 of the 22 patients (Table 1 ). In patients $1-3$, who had major clinical responses, a very small lesion of viable invasive ductal carcinoma (IDC) was seen adjacent to extensive ductal carcinoma in situ (DCIS) in the resection material. These findings indicate a discrepancy between clinical and pathological complete remissions, but more importantly a lack of chemosensitivity of DCIS. Since the extent of DCIS is not predicted by prechemotherapy cytology nor expected from the distribution of mammographic microcalcifications $[8,9]$, cxtensive DCIS may still be found in resection material after a major response to induction chemotherapy of the invasive tumour.

Table 1. Patients' characteristics

\begin{tabular}{lccccl}
\hline Patient & Clinical stage & Response & Surgery & \multicolumn{2}{l}{ Histopathology } \\
\hline 1 & T2N2 $(2.5 \mathrm{~cm})$ & CR & L$^{*}$ & DCIS & IDC \\
2 & T1N2 $(2 \mathrm{~cm})$ & CR & Q $^{*}$ & DCIS & IDC \\
3 & T4bN2 $(6 \mathrm{~cm})$ & PR $(1.8 \mathrm{~cm})$ & M & DCIS & IDC \\
4 & T2N1 $(4 \mathrm{~cm})$ & CR & $\mathrm{L}^{*}$ & - & IDC \\
5 & T1N2 $(1.5 \mathrm{~cm})$ & MR $(1.1 \mathrm{~cm})$ & $\mathrm{L}^{*}$ & - & ILC \\
6 & T2N0 $(4 \mathrm{~cm})$ & MR $(2.1 \mathrm{~cm})$ & $\mathrm{L}^{*}$ & LCIS & ILC \\
7 & T4cN1 $(5 \mathrm{~cm})$ & PR $(1.4 \mathrm{~cm})$ & $\mathrm{M}$ & - & ILC \\
\hline
\end{tabular}

CR, complete response; PR, partial response; $M R$, minor response; L, lumpectomy; $Q$, quadrantectomy; $M$, radical mastectomy; DCIS, ductal carcinoma in situ; LCIS, lobular carcinoma in situ; IDC, invasive ductal carcinoma; ILC, invasive lobular carcinoma. *After ultrasound localisation.

\section{Problems with the Evaluation of Response After Induction Chemotherapy in Breast Cancer}

\section{C.K. Mannesse, R. van Pel, J. van Spengler, C. H. van Eijck and T.A.W. Splinter}

INDUCTION CHEMOTHERAPY has become part of the standard treatment of locally advanced breast cancer. Recently, it has also been used to induce "lumpectability" in tumours larger than
Correspondence to C.K. Mannesse.

C.K. Mannesse and T.A.W. Splinter are at the Department of Medical Oncology; R. van Pel is at the Department of Pathology; J. van Spengler is at the Department of Radiology; C.H. van Eijck is at the Department of Surgery; and C.K. Mannesse is also at the Department of Internal Medicine, University Hospital Rotterdam Dijkzigt, Erasmus University Rotterdam, The Netherlands.

Received 13 Mar. 1995; accepted 16 May 1995. 
A second problem, related to the discrepancy between clinical and pathological complete remission, is the localisation of the prechemotherapy site of the tumour in a case of clinical complete remission (CR). Patient 4 had obtained a clinical $C R$ and underwent lumpectomy after ultrasound localisation of a doubtful remaining lesion. In the margin of the lump, a very small amount of viable IDC was found, and more IDC in the mastectomy specimen.

The third problem was a major discrepancy between the clinical and pathological response. 3 patients (5-7) had a small lesion after induction chemotherapy. In 2 patients, a lumpectomy and in 1 patient a mastectomy was performed, which were irradical because of the presence of multifocal tumour rests. In all patients, invasive lobular carcinoma (ILC) was found, which is known for its multicentric diffuse growth pattern [10, 11].

Although there have been reports on the discrepancy between clinical and pathological evaluations of response after induction chemotherapy in breast cancer $[1,12]$, our experience indicates a cautious approach should be taken in the use of chemotherapy to induce "lumpectability", and it is recommended that the response is verified pathologically, especially in patients with CIS and/or ILC.

1. Bonadonna G, Veronesi U, Brambilla C, et al. Primary chemotherapy to avoid mastectomy in tumors with diameters of three centimeters or more. 7 Natl Cancer Inst 1990, 82, 1539-1545.

2. Mauriac L, Durand $M$, Avril A, Dilhuydy J-M. Effects of primary chemotherapy in conservative treatment of breast cancer patients with operable tumors larger than $3 \mathrm{~cm}$. Ann Oncol 1991, 2, 347-354.

3. Jones AL, Smith IE, O'Brien MER, et al. Phase II study of continuous infusion fluorouracil with epirubicin and cisplatin in patients with metastatic and locally advanced breast cancer: an active new regimen. 7 Clin Oncol 1994, 12, 1259-1265.

4. Jacquillat C, Weil M, Baillet F, et al. Results of neoadjuvant chemotherapy and radiation therapy in the breast-conserving treatment of 250 patients with all stages of infiltrative breast cancer. Cancer 1990, 66, 119-129.

5. Bonadonna G, Valagussa $P$, Brambilla C, et al. Responsc to primary chemotherapy increases rates of breast preservation and correlates with prognosis. Proc Am Soc Clin Oncol 1994, 13 107, Abstr. 230.

6. Khayat $\mathrm{D}$, Weil $M$, Auclerc $\mathrm{G}$, et al. Clinical relevance of tumor regression in neoadjuvant chemotherapy in breast cancer revisited. Proc Am Soc Clin Oncol 1994, 13, 75, Abstr. 99.

7. WHO (1979). Handbook of Reporting Results of Cancer Treatment. Offset publication No 48. World Health Organization, Geneva.

8. Holland R, Connolly JL, Gelman R, et al. The presence of an extensive intraductal component following a limited excision correlates with prominent residual disease in the remainder of the breast. f Clin Oncol 1990, 8, 113-118.

9. Holland R, Hendriks JHCL, Verbeek ALM, et al. Extent, distribution, and mammographic/histological correlationns of breast ductal carcinoma in situ. Lancet 1990, 335, 519-522.

10. Helvie MA, Paramagul C, Oberman HA, et al. Invasive lobular carcinoma; imaging features and clinical detection. Invest Radiol 1993, 28, 202-207.

11. Poen JC, Tran L, Juillard G, et al. Conservation therapy for invasive lobular carcinoma of the breast. Cancer 1992, 69, 2789-2795.

12. Feldman LD, Hortobagyi GN, Buzdar AU, et al. Pathological assessment of response to induction chemotherapy in breast cancer. Cancer Res 1986, 46, 2578-2581.
European foumal of Cancer Vol. 31A, No. 11, pp. 1887-1888, 1995. Copyright (C) 1995 Elsevier Science Ltd Printed in Great Britain. All rights reserved $0959-8049 / 95 \$ 9.50+0.00$

0959-8049(95)00397-5

\section{Sequential Chemotherapy, Beta Interferon, Retinoids and Tamoxifen in the Treatment of Metastatic Breast Cancer. A Pilot Study}

\author{
F. Recchia, S. Rea, G. Corrao, \\ A. Fingerhut and L. Frati
}

CHEMotherapy (CT) for metastatic breast cancer remains palliative, and no clear therapeutic strategy has yet been established for responders with subclinical minimal residual disease. In vitro studies have shown that interferons (IFN) and retinoids inhibit the growth of oestrogen receptor positive $(E R+)$ and negative (ER-) breast cancer cell lines $[1,2]$, and sensitise them to the antiproliferative action of anti-oestrogens through the enhancement of oestrogen receptors [3-6].

This rationale led us to undertake a phase II pilot study to explore the attractive working hypothesis of administering two non-cross-resistant $\mathrm{CT}$ regimens, followed by maintenance therapy, with $\beta$-IFN, retinoids and tamoxifen (TAM) in a group of patients with poor prognosis metastatic breast cancer. Eligibility criteria included pathologically documented measurable or evaluable breast cancer; age $<75$ years; performance status $<3$; no anthracycline chemotherapy; recovery from previous radiotherapy and/or CT with WBC count $>3500 \mathrm{~mm}^{3}$, platelet count $>100000 \mathrm{~mm}^{3}$; normal kidney and cardiovascular function and written informed consent. Induction CT was 4-epidoxorubicin $60 \mathrm{mg} / \mathrm{m}^{2} /$ day 1 , cyclophosphamide $500 \mathrm{mg} / \mathrm{m}^{2} /$ day 1 , vincristine $2 \mathrm{mg}$ day 1,5 -fluorouracil $500 \mathrm{mg} / \mathrm{m}^{2}$ days 1 and 8 , prednisone $50 \mathrm{mg}$ days $1-5$, and this was repeated every 3 weeks for six courses, followed by mitomycin-c and mitoxantrone $10 \mathrm{mg} /$ $\mathrm{m}^{2}$, methotrexate $40 \mathrm{mg} / \mathrm{m}^{2}$ day 1 for two courses every 4 weeks. Maintenance therapy for responders was $\beta$-IFN $1 \times 10^{6} \mathrm{IU} / \mathrm{m}^{2}$ three times a week, retinyl palmitate 50000 IU twice daily, TAM $10 \mathrm{mg}$ three times daily, until disease relapse.

Responses and toxicities were categorised according to WHO criteria. 36 patients were enrolled in the trial from January 1987 to January 1992. Median age was 61 years (range 37-74); 4 were premenopausal and 32 postmenopausal. Median disease-free interval was 19 months (range 1-28) for 27 patients, while 9 patients had metastases at the time of diagnosis. All patients had

Correspondence to F. Recchia at Via Rossetti 1, 67056 LUCO DEI MARSI (AQ), Italy.

F. Recchia is at the Division of Internal Medicine (Oncology Unit), Civil Hospital, 67051 Avezzano; S. Rea, A. Fingerhut, F. Recchia and L. Frati are also at "Centro di Riferimento Oncologico Franco-Italiano", Moterotondo, Rome; S. Rea is also at the Surgical Oncology University of L'Aquila; G. Corrao is at the Medical Statistics and Biometry University of L'Aquila; and L. Frati is also at the General Pathology University "La Sapienza", Rome, Italy.

A. Fingerhut was a visiting Professor at the Surgical Oncology University of L'Aquila, Italy.

Revised 12 Jun. 1995; accepted 7 Jul. 1995. 